Kaliopa DIMITROVSKA ANDREWS Matej NIKŠıč

\section{The role of urban design in internalised settlement development}

\section{Introduction}

One of the main characteristics of urban development in the passed decades was extensive use of land with small population densities that resulted in built-up areas spreading much faster than population growth conditioned (Research\&Services Centre, 1997). With recognition of negative consequences of such developments and strengthening of the sustainable development paradigm, a strategic reorientation occurred towards internalised settlement development or infill development. This means redirection of development to vacant or extensively used areas within existing urban surfaces (NCEH, 2005). The goal of such development is more compact urban form that has several advantages over the extensive variety, in short it:

- contributes to preservation of natural hinterland of cities,

- occupies smaller areas and has higher energy efficiency (transport, heating),

- enables combining of housing and working inside small distance,

- ensures the critical mass of people for public programmes,

- reduces traffic needs

- increases the city budget income per property unit.

In the Slovene strategic spatial documents (2004) inner development of settlements has also been defined as a primary mode of future development, which has to be given the priority over the expansion of building into new areas. The goal is better utilisation and higher quality use of empty or unsuitably used land. It is achieved by: changes of use of existing objects and areas, congesting extensively used populated areas with revitalisation, renovation, reurbanisation, reconstruction and rehabilitation of degraded areas. Besides spatial goals, inner development should also contribute to economical development, solving of social problems, raising housing standards and balancing the ratio between built-up and green surfaces in cities.

In practice this type of investment is much riskier, than building on less demanding vacant areas (so called greenfield development). Often empty lots inside already urbanised areas remain vacant for arguable reasons: less suitable land base (carrying capacity, swampiness), local dwellers opposing the new development, (over)restrictive urban planning and design conditions on the part of planning authorities, which all increases expenses of such investments.

Because of such conditions local urban planning services are confronted with a responsible task of offering investors incentives to invest in such areas, while at the same time ensuring the contextual positioning of the new object with the area. Moreover, since the average investor, following the motive of highest possible return, often neglects existing architectural-urbanistic contexts and proposes buildings with design or function poorly corresponding to the setting. The role of urban design regulation is also important for ensuring public interests.

\section{Establishment of urban design and economic criteria}

When looking for criteria for coherent inner development of cities we have to understand both past traditions of building urban space and contemporary (economical) trends and rules. Most of Central and Eastern European planning originates from Sitte's basic work "City Planning According to Artistic Principles « (1895). In the case of Ljubljana his ideas can bee seen in the general town plan dating to the beginning of the previous century (Sitte, 1895, Koch, 1910, Plecnik, 1928) as well as in implementations of Plecik's urban design and sequential relation to city from 1930 to1950 (Bentley in Gržan-Butina, 1983). In Ljubljana this aesthetic tradition is still present and importantly co-designs streets squares and river bank areas in the city's central part.

When establishing proper evaluation method, suitable to Slovene spatial reality, apart from the mentioned urban design tradition individual theoretical results that could give adequate starting points for internal settlement development projects, successful foreign planning practices are also useful. British and North American city planning and urban design systems offering the broadest array of theories and practical intervention tools seem especially useful. They are informative from the standpoint of marketing the city and negotiation strategies (for example successful planning systems of cities, such as: Birmingham, London, San Francisco, Portland, Boston) but there are also some useful ideas on the level of urban design guidelines and short instructions and coding mechanisms for individual locations.

When creating suitable evaluation methods to measure urban design qualities and economical effectiveness of the city projects by replacement and supplement building, some incentives for enhancement of quality urban planning, such as Quality in the city and in the countryside (HMSO, 1996), Vital and viable city centres (HMSO, 1994), were also analysed, as well as the review of the planned control of urban designing in Great Britain carried out by John Punter (1997). The results of analyses show that in designing of urban areas there is a tendency to move from mostly visually/perceptively oriented approaches of the picturesque city image (Lynch, 1960, 1981; Cullen, 1971; Appleyard, 1981) to more complex approaches of studying urban design quality measures such as e.g. responsive environment, new urbanism, urban renaissance (Bentley and others,1985; Tibbalds, 1992; Duany and Plater-Zyberk, 1991; Llewelyn-Davies, 2000)

Using that base Dimitrovska Andrews and Butina Watson (2001) have developed a methodology that is aligned to basic principles of quality city form and consists of three main categories (tables):

- context and general compatibility (location, use, positioning, the characteristics and measure of the urban pattern);

- organisation and external impacts (the quality of public, influence of physical quality, landscape arranging and attractiveness);

- architecture and design of details (the most sensitive area of urban designing: types of buildings, style, facades, details and materials). 
To identify these elements the urban design criteria of quality are used: identity, permeability, diversity, legibility, visual suitability, adaptability and visual and symbolic riches (Dimitrovska Andrews et al., 1994, page 43-40).

Beside architectural and urban design criteria the economical aspect is also important. By considering land purchase and construction expenses, as well as market value of the investment, it is possible to derive the profitability of the project and upon this basis designate added value (internal degree of revenue), that can be redirected into fulfilment of local needs such as public spaces, environment improvements, social programmes etc. In the negotiation process, as demonstrated by two examples, described in the next chapter, planners can be aided by simple calculation models simulating the ratio between construction expenses and profit (table 2). (Dimitrovska Andrews et al., 1994, pp. 41-44)

\section{Urban-design evaluation of the condominium Trnovski pristan and residential building Gradaška in Ljubljana}

In the last decade Ljubljana witnessed both the spreading of the city onto new, formerly vacant areas and inward growth through reconstruction and extensions. Especially the latter presents a great urban design challenge. In continuation we shall look at two examples of housing building in the city centre.

The buildings were designed by the architectural team Sadar Vuga architects, who seek to break with the "conventional « design process and therefore takes inspiration in the world of visual, acoustic and written information with the aim of creating fresh and lasting architectural products (www.sadarvuga.com, 2004). Aspiring for different and attractive is fil rouge of the design process that seeks solutions consistent with client wishes, while, as the further analysis will show, leaves aside the characteristics of the surrounding space.

To understand the motives that have brought to such design we shall take a look at considerations guiding the authors. Design of the Trnovski pristan condominium is based on three premises: house in the park or park in the house, unique entry hall and variety of highly individualised flats. The building should offer a unique residential environment, while dynamic openings should ensure optimal illumination. There is no consideration of the relation to neighbouring objects. In the case of Gradaška housing object such consideration is even denied, since the object is supposed to be independent to the nearby village object and should, as opposed to their rural character, air a metropolitan flavour. Rather then delicately placing this development into a sensitive environment the designers turned their attention to internal organisation of the building.

Absence of criteria, defined by the urban design profession as spatial positioning, is obvious in the architect's understanding, especially of those characteristic for contextual building design and external efficiency (table 1). Both objects are located in city districts with clearly recognisable morphological structure - the first one on the rim of the characteristic Krakovo neighbourhood with particular cha- racter derived from its well-preserved village structure, another in the quarter of post-war single family houses.

While the object in Gradaška follows the in-depth development of the Krakovo built-up area, its volumes are grossly over-dimensioned. Its micro-positioning also neglects that the existing street front of Gradaška Street is compact - thus it faces a firewall of the neighbouring building instead of covering it and continuing, i.e. completing the street front. Justification that the displacement is necessary for illumination of the existing objects in the back is irrelevant since achieving that would demand proper horizontal displacement and lesser height of the new building. The only positive aspect in the given situation seem to be displacement of the upper story into the interior of the plot since the cornice of the street facing part of the building follows the cornices of the neighbouring objects and at the same time preserves views of the castle tower from the stairway of the Trnovo church. The new building is less successful in general relation to the public space - even though it adequately follows the built-up line of the street, it faces this same street with a firewall type of the facade, creating a dead - inactive street edge.

In the case of Trnovo condominium the new building's ground plan follows the shapes of an industrial object formerly occupying this site, even though the former was already a foreign body, not only functionally but also morphologically, i.e. its flatness digressed from nodal and row (terraced) building in the area. Reurbanisation was an excellent opportunity to remove such imbalance, but was (we're guessing) shunned because pressure for maximised exploitation of the property. Equally unsuitable is the relation towards neighbouring objects to the South with the new building being higher by more than a floor - even though it isn't problematic when observed from the street, i.e. perspective shortening, the height ratio towards surrounding singlefloor buildings is certainly inappropriate.

The function of both objects is consistent with existing use of land, but in the case of the Gradaška building, lying by a stream, its firewall type facade against the street is an again encountered issue - following the example of the opposite bank, here too a pleasant, cafe style street-scape atmosphere could once develop - an option now blocked by the mentioned concept.

The arising question is, what type of built-up structure would be more suitable for the existing morphology of the space, while still ensuring adequate profitability? A test was done to check economical efficiency using the method developed by Dimitrovska Andrews and Butina Watson (2001). It turned out that in the case of the Trnovo condominium, construction of five small villa-blocks, relating much better to the morphology of the area, would result in equal number of (slightly smaller) flats, decreasing profitability by only $1 \%$. (25.62 to $24.70 \%$ ). Construction of multi-flat semi-detached housing inside the building lot wouldn't significantly decrease profitability either $(3 \%)$. Both presented cases would follow much better the morphology of the area and round up more harmoniously the appearance of the city district as a whole (table 3 ).

We arrived at similar results in the case of the plot by the Gradašcica Stream. The comb shaped building and separate object in the street front correspond better to the morphology of the area and achieve only $3 \%$ lower profitability than the object presently being built there. 


\section{Conclusion}

Internalised development, in the sense of reconstruction, replacement and supplement building, defined as a primal mode of further development within both the paradigm of sustainable development and Slovene strategic documents, demands the development of suitable tools for initiating and evaluating contextual placement of new buildings into the existing urban environment that would consider both urban design quality and economic efficiency. The suggested method (Dimitrovska Andrews and others 1994; Dimitrovska Andrews, Butina Watson 2001), considering both basic principles of quality, i.e. urban form/image and investment economy, can be used in the following examples:

- promotion of the development potential of the city (»marketing the city «);

- planning (as the methodological framework for negotiations of interests among different participants);

- designing (to evaluate contextual quality and economical efficiency of building concept variations for individual sites).

The analysed cases, Trnovski pristan Condominium and Gradaška residential building, are telling for the practise in Ljubljana, mostly because they are drawing attention to possibilities offered by re-urbanisation in the sense of rounding up built-up areas in characteristic city districts. Unfortunately an all too often occurrence is that the term "added value « is understood in a sense of negation of the existing characteristics and qualities of a given space instead of the opposite. Isn't added value architecture the one that qualitatively replenishes the space, emphasises and upgrades it's characteristics and thus contributes to more recognisable city structure on the general level? The possibilities for an individual, author's mark, regarded so highly by modern architecture, can be found also within such framework.

Assist. prof. Kaliopa Dimitrovska Andrews, Ph.D., architect; Matej Nikšič, M.A., architect, Urban planning institute of the Republic of Slovenia, Ljubljana

E-mail: kaliopa.dimitrovska@urbinstitut.si; matej.niksic@urbinstitut.si
For sources and literature turn to page 28.

Illustrations:

Table 1: Design criteria and physical structures

Table 2: Comparative urban-design analysis of the Trnovski pristan condominium and residential building Gradaška in Ljubljana

Table 3: Evaluation of economical efficiency of the investment - case: Trnovski pristan condominium

Figure 1: Location of objects

Figure 2: Urbanistic-design presentation of Trnovski pristan condominium and housing object Gradaška in Ljubljana

Figure 3: Different options 